\title{
The Relationship between Consumers' Public Self- consciousness and their Purchase Intention of the New Luxury Goods
}

\author{
Jiaxuan $\mathrm{Xu}^{*}$ \\ Jiangnan University, Wuxi 214000, Jiangsu Province, China \\ *Corresponding author: Jiaxuan Xu, 13383578008@163.com
}

\begin{abstract}
The era of consumption upgrade has begun due to the rapid economic development. Nowadays, the new luxury consumption is prevailing, and China has emerged as the primary consumer of these luxury goods. Based on the public selfconsciousness of consumers, the relationship between this aspect and consumers' purchase intentions of the new luxury goods is explored. This study investigated the impact of consumers' public self-consciousness on their willingness to purchase new luxury goods, validated the proposed hypothesis by design experiments, and used the linear regression analysis of the experimental data. This study showed that the higher the consumer's public self-consciousness, the more inclined they were to purchase these luxury goods. The findings of this study would be helpful to expand and enrich the research of the new luxury consumption behaviors in consideration that public self-consciousness is hardly reflected in recent research. Hence, this study would enlighten and acts as a significant reference for companies of the new luxury goods to develop more effective marketing strategies.
\end{abstract}

Keywords: New luxury; Public self-consciousness; Purchase intention; Consumption behaviors; Luxury goods market

Publication date: June 2021; Online publication: June 30, 2021

\section{Introduction}

With the transformation in purchase intention among modern-day consumers, consumer groups in the luxury market are diversified. This does not only include the upper income groups, but also, many middleclass consumers who are inclined to pursue unique and personal values. The transformation of consumers' purchasing behavior promoted the mass luxury consumption phenomenon; thus, resulted in the birth of new types of luxury goods which are termed as "entry luxury" or "new luxury" by scholars.

Studies have shown that public self-consciousness promoted conspicuous consumptions which caused an increased in consumers' purchases of traditional luxury goods. Although the new luxury goods have similarities with the traditional ones in regard to their meaning, technology, industrial designs, and technical details, they are still distinct in terms of essence. This indicates that public self-consciousness may not have a substantial impact on the purchases of new luxury goods. The jury is still out on whether public selfconsciousness affects the purchase intention of new luxury goods. This issue is investigated and the relationship between the two is discussed in this paper.

The purpose of this study was to determine the effect of consumers' public self-consciousness on their purchase intentions of the new luxury goods, and eventually contributing to theoretical and practical operations. The results of this study have great significance in interpreting the phenomena of current consumption, exploring the characteristics of the new luxury consumption behaviors, and formulating marketing strategies for these goods. 


\section{Literature Review}

\subsection{The new luxury}

\subsubsection{Traditional luxury and the new luxury}

Traditional luxuries are regarded as a type of consumer goods with exclusivity, yet scarce, beyond the general demand. They are non-essentials with higher intangible value compared with the tangible effects. In current studies, Guo and Su defined luxury as the possession and enjoyment of the upper-class consumers in a particular society. ${ }^{[1]}$

The new luxury had evolved based on traditional luxury. In 2005, Silverstein, Fiske, and Barmante developed the concept of the new luxury in which they defined it as products or services that are of higher quality and better taste compared to similar goods yet, having an identified price without being prohibitively expensive. ${ }^{[2]}$ The new luxury which drifts at the edge of luxury products is between the ordinary consumer goods and the traditional luxuries. In a profound way, the new luxury are goods with the voguish side of traditional luxuries but are distinguished from traditional luxuries by a larger audience.

\subsubsection{Current research on the new luxury}

The research perspectives of new luxury goods are more in the vassal level in comparison to traditional luxuries, whereby new luxuries are considered to be the "second best." Therefore, many studies on new luxury goods are based on traditional luxuries. Although some research have failed to develop empirical studies on the new luxury, scholars were still able to discover its' consumers distinctive behavior in the process, whereby the consumers have different purchase intention from consumers of traditional luxuries. Latzler suggested differences in the consumption behaviors between consumers of traditional luxuries and new luxuries whereby "spending money to boast is related to traditional luxury while using money on one thing and focusing on its practicality is related to the new luxury."[3] Therefore, it is necessary to separate the new luxury from the frame of traditional luxury and conduct a separate study altogether.

\subsection{Public self-consciousness and consumer behavior}

Public self-consciousness is one of the components of self-consciousness that represents the awareness of oneself as a social and public object. It is the tendency to weigh one's individuality in the sense of public display such as one's overt behavior, mannerisms, stylistic quirks, and expressive qualities. ${ }^{[4]}$

A few research regarding public self-consciousness revealed that public self-consciousness is related to sensitivity in social interaction. There is evidence that public self-awareness is associated with conspicuous consumptions. For example, Nezlek and Emilia proved that people with higher self-consciousness generally have higher ostentation intentions. They are regular cosmetics consumers with keen interests in clothes that would reflect their own value. ${ }^{[5]}$

\subsection{Literature evaluation}

From existing literatures on the new luxury consumptions and public self-consciousness, scholars in related fields have confirmed several differences between new luxuries and traditional ones. However, the interests in new luxury consumption still needs to be strengthened. The research on the consumption behavior of new luxury goods are still insufficient with only a sole perspective; hence, failing to provide a comprehensive and in-depth explanation for the consumption behaviors of new luxuries.

In addition, there is a lack of systematic and theoretical research about the effect of public selfconsciousness on the purchase of new luxuries. Despite some ostentatious intentions in purchasing new luxuries, the consumption of these goods may present with different intentions along with time such as, 
self-enjoyment. Thus, whether public self-consciousness would influence the consumer's willingness to purchase new luxuries and the extent of this influence need to be investigated.

\section{Research Design}

\subsection{Hypothesis development}

A few research have shown that public self-consciousness exerted significant impact on various conspicuous consumption behaviors. However, in view of the new luxury, Li stated that modern-day consumption has gradually shifted from the "show off phase" to the "integration phase" whereby new luxury consumers tend to purchase them as part of their lifestyle. In contrast to boasting, they emphasize on enjoying the functions of the new luxuries such as their quality and highlighted characteristics. ${ }^{[6]}$ In this case, the jury is still out on whether public self-consciousness would affect the purchase of new luxury goods the same way as traditional luxury goods.

In the analysis of existing research, this paper believes that the new luxury still retains a part of the traditional luxury. This is because, the consumers' motives for buying luxuries have not yet fully shifted from "showing off" to "functional enjoyment," indicating that the impact of ostentation on the purchase of new luxuries is not insignificant to be disregarded. Therefore, the following hypothesis is proposed: The intensity of consumers' public self-consciousness is positively correlated with their purchase intention of new luxury goods.

\subsection{Research method}

In order to explore the relationship between the consumers' public self-consciousness and their willingness to purchase new luxury goods, this study adopted the questionnaire method. Two hundred questionnaires were randomly distributed to college students in the library of Jiangnan University and were then, collected. 174 valid questionnaires were attained with an effective response rate of $87 \%$. All the respondents voluntarily participated in this study with informed consent. The questionnaires came with a comprehensive guide which stated the purpose of the survey, filling requirements, and confidentiality pledges.

To control other influencing factors of the respondent's purchase intention, the study was done in a pre-booked study room; which provided a quiet environment for the respondents to fill in the questionnaires; thus, largely avoiding the interference of external factors.

\subsection{Scale design and the measurement principle}

\subsubsection{Measurement of public self-consciousness levels}

The public self-consciousness levels of the respondents were measured using a Public Self-Consciousness Scale (PUSC) which was derived from the Fenigstein's Self Consciousness Scale (SCS). ${ }^{[7]}$ It had seven statements that reflected different aspects of the respondents' public self-consciousness. The degree of agreement described in the PUSC was measured using the Likert 5-point method (1 indicated "totally disagree" while 5 indicated "completely agree"). The results were determined by the cumulative score of 7 items contained in the scale.

\subsubsection{Measurement of purchase intentions of new luxuries}

The scale used for consumers' purchase intentions was adapted from Dawar's research, which included four descriptions that indicated the consumers' willingness to purchase new luxuries. ${ }^{[8]}$ The degree of agreement was also measured with the Likert 5-point method as mentioned above. The results were determined by the cumulative score of the four items in the scale. 


\section{Hypothesis Verification and Conclusion}

\subsection{Data analysis}

This study used the public self-consciousness score as the independent variable while the willingness to purchase new luxuries score was used as the dependent variable in the linear regression analysis. The SPSSAU software was used based on the original data collected from the 174 respondents. The following results were obtained as below.

From the F-test of the model, it was found that the significance level of the model was large enough $(\mathrm{F}=134.611, \mathrm{p}=2.33 \mathrm{E}-23<0.05)$, indicating that the public self-consciousness score had an impact on the score for purchase intention of new luxury products. Since the value of R Square was 0.439, and the Regression Coefficient value $(\mathrm{R})$ was greater than 0 (approximately 0.66), these illustrated that the influence was positive. In other words, the higher the respondent's score in the public self-consciousness scale, the more willing they were to purchase new luxuries.

Based on the analysis of these results, the statement that "Public self-consciousness has a significantly positive impact on the purchase intention of new luxuries" is drawn.

\subsection{Conclusion}

This study explored the intention of purchasing new luxury products in view of public self-consciousness. Based on the linear regression analysis of the collected data, this paper effectively proved the validity of the hypothesis.

\section{Discussion}

\subsection{Theoretical implications}

In theoretical sense, this study explored the influence of consumers' public self-consciousness on their intentions to purchase new luxury products. This functions as enlightenment and future research reference for the consumption behaviors of new luxuries. In addition to that, based on previous studies on traditional luxury goods and new luxuries, this paper pointed out and distinguished the differences between the two while further clarifying the boundaries between them. Hence, providing a theoretical basis for more relevant studies in the transformation of the modern-day mass consumption trends.

\subsection{Practical implications}

In practical sense, this research would benefit the new luxury marketers to gain deeper insights into the perspectives of targeted consumer groups. By understanding their behaviors, it provides an opportunity for improvement in the luxury goods market. In regard to the deduction that consumers with higher levels of public self-consciousness were more likely to purchase new luxuries, the new luxury industry is encouraged to distinguish and pay more attention to these group of consumers with higher public self-consciousness. This can be done in consideration of consumer's behaviors such as frequent purchase of clothes and cosmetics. Subsequently, the industry should review specific marketing strategies in combination with their ideology to promote the development of the new luxury goods market.

\subsection{Limitations}

Although there are some theoretical and practical significance, this paper still has limitations, whereby the data sample in this study were monotonous to a certain degree. In regard to that, this research was conducted in Jiangnan University whereby the sample group comprised of 18 to 22-year-old college students, which signified only a small distribution in the social strata. Although it is known that the leading group of new 
luxury consumption is among the post-90s generation, the single, specific sample still limits the universality of this conclusion.

\section{Disclosure statement}

The author declares no conflict of interest.

\section{References}

[1] Guo PJ, Su Y, 2007, An Empirical Research on Luxury Consumption Behavior of Chinese Consumers. Management Review, (09): 10-17, 65.

[2] Michael S, Neil F, John B, 2005, Luxury is in fashion. Publishing House of Electronics Industry.

[3] Wang J, 2007, An Analysis of the consumption motive and consumption pattern of new luxury goods. China Market, (39): 172-173.

[4] Zeng FE, Zou Z, Tao R, 2018, Does Personalization Marketing Trigger Privacy Concern All the Time: Based on the Moderation of Anthropomorphic Communication. Nankai Business Review, 21(05): 8392.

[5] Nezlek JB, Emilia M, Cypryańska M, 2018, Self-presentational motives and public self-consciousness: why do people dress a certain way?. Journal of Personality, : 87.

[6] Li X, 2014, Mass consumption of luxury and new luxury product marketing strategy adjustment. Prices Monthly, 000(006): 58-61.

[7] Fishbein M, Ajzen I, 1975, "Belief, Attitude, Intention, and Behavior: An Introduction to Theory and Research". Reading, Addison-Wesley, MA.

[8] Dawar N, 1996, Extensions of broad brands: The role of retrieval in evaluations of fit. Journal of Consumer Psychology, 5(2): 189-207. 